\title{
OPEN The SMOS-Derived Soil Water EXtent and equivalent layer thickness facilitate determination of soil water resources
}

\author{
Boguslaw Usowicz ${ }^{\bowtie}$, Mateusz Lukowski \& Jerzy Lipiec
}

The assessment of water resources in soil is important in understanding the water cycle in the natural environment and the processes of water exchange between the soil and the atmosphere. The main objective of the study was to assess water resources (in 2010-2013) in the topsoil from satellite (SMOS) and in situ (ground) measurements using the SWEX_PD approach (Soil Water EXtent at Penetration Depth). The SWEX_PD is a result of multiplying soil moisture (SM) and radiation penetration depth $(P D)$ for each pixel derived from the SMOS satellite. The $P D$, being a manifold of the wavelength $\lambda_{0}$ equal to $21 \mathrm{~cm}$, was determined from the weekly SMOS L2 measurement data based on the real and imaginary part of complex dielectric constant. The SWEX_PD data were compared with soil water resources $(W R$ ) calculated from the sum of components derived from multiplication of soil moisture (SM) and layer thickness in nine agrometeorological stations located along the eastern border of Poland. Each study site consisted of seven neighbouring Discrete Global Grid pixels (nodes spaced at $15 \mathrm{~km}$ ) including the central ones with agrometeorological stations. The study area included different types of soils and land covers. The agreement between the water resources obtained from the SWEX_PD and ground measurements $(W R)$ was quantified using classical statistics and BlandAltman's plots. Calibrated Layer Thickness $\left(C L T=d_{\text {bias }}\right)$ from 8 to $28 \mathrm{~cm}$ was obtained with a low values of bias (close to zero), limits of agreements, and confidence intervals for all the SWEX_PD, depending on the pixel location. The results revealed that the use of the SWEX_PD for assessing soil water resources is the most reliable approach in the study area. Additionally, the data from Bland-Altman plots and the equation proposed in these studies allowed calculation of the Equivalent Layer Thickness $\left(E L T=d_{e i}^{S W E X}\right)$, which corresponds to the water resources derived from the SMOS satellite at the same time as (SM) measurements performed in the agrometeorological stations. The ranges of the mean, standard deviation, minimum, maximum, and coefficient of variation (CV) of ELT among all pixels and stations were $8.28-28.7 \mathrm{~cm}, 3.27-12.66 \mathrm{~cm}, 3.03-10.87 \mathrm{~cm}, 19.23-94.97 \mathrm{~cm}$, and 24.72-98.79\%, respectively. The ranges of the characteristics depended on environmental conditions and their means were close to the values of the calibrated layer thickness. The impacts of soil texture, organic matter, vegetation, and their interactive effects on the differentiation and agreement of soil water resources obtained from SWEX_PD vs. data from ground measurements in the study area are discussed. Further studies are required to address the impact of the environmental factors to improve the assessment of soil water resources based on satellite SM products (retrievals).

Soil water resources play a significant role in the agriculture and the entire environment ${ }^{1-4}$. They influence soil-atmosphere relations through exchange of energy, fluxes of water and greenhouse gases, and latent heat flux during evaporation ${ }^{5-8}$. Consequently, they are an important variable for weather predicting and climate projection $^{9-11}$, including forecasting extreme events ${ }^{12}$. Monitoring the soil moisture and water resources is necessary for numerous applications such as agricultural drought assessment, irrigation scheduling, soil and crop management ${ }^{13,14}$, and ground water recharge ${ }^{15}$.

Soil water resources data can be acquired from ground-based measurements or globally, using satellite techniques ${ }^{16,17}$. Satellite remote sensing facilitates investigation of large-scale areas where field observations are 
insufficient to provide data. Different frequencies including X, C, and L bands are used in space-borne satellites to estimate soil moisture content ${ }^{18-20}$. C and X bands have been used in some satellite sensors, e.g. AMSR-E and ASCAT, to determine surface (skin) soil wetness, whereas L-band (microwave) radiometers help to analyse nearsurface $(0-5 \mathrm{~cm})$ soil moisture. Research indicates that the use of the L-band $(21 \mathrm{~cm})(1.4-1.427 \mathrm{GHz})$ is the most promising radiometry approach for estimation of soil moisture due to its higher sensitivity to the dielectric properties of soil and lower sensitivity to the vegetation layer ${ }^{11,19,21}$. Since 2009, this band has been used in the Soil Moisture and Ocean Salinity (SMOS) mission for delivering the brightness temperature and global mapping of near-surface $(0-5 \mathrm{~cm})$ soil moisture at a temporal resolution of 2 to 3 days ${ }^{22,23}$. In addition, this frequency is within the protected band for radio astronomy and exhibits minimum radio-frequency interference (RFI) ${ }^{24}$.

Microwave remote sensing of topsoil moisture data has been useful for many Earth systems including agriculture, weather forecasting, and determination of landslide potential and ground trafficability ${ }^{19}$. The usefulness and applicability of remotely sensed topsoil SM has been increased by new developments allowing assessment of water available for plants in the root-zone based on the topsoil moisture at a regional ${ }^{25,26}$ and global scale gal $^{27}$. Reviews of relevant research literature indicate that the potential for the use of satellite global soil moisture products for many societal applications can be further enhanced by refining or developing adaptative scaling, data assimilation, and modelling schemes ${ }^{19,22}$.

An important parameter of satellite remote sensing is the radiation penetration depth (synonymously used with "sensing depth"), which corresponds to the depth derived from the satellite and is defined as a depth at which the intensity of electromagnetic waves decreases (is attenuated) by a factor of $1 / e$ times $^{28}$ (about $37 \%$ ), where $e$ is Euler's number equal to approximately 2.718 . The penetration capability of microwave signals decreases with the increasing dielectric constant of the soil due to the increasing moisture content ${ }^{29}$. Furthermore, the Penetration Depth $(P D)$ can be influenced by soil properties and land cover through their water content and attenuation at the L-band ${ }^{19,30}$. Besides, the $P D$ decreases as the incident angle of the sensors increases ${ }^{29}$. Due to these interferences (relations), the retrievals of soil moisture and temperature profile information from diverse satellites can be comparable after precise determination of the penetration depths ${ }^{11,31,32}$.

Validation and calibration of space-borne observations by comparison with ground measurements are crucial in evaluating the quality of satellite products ${ }^{17}$. Therefore, in situ soil moisture monitoring systems have been established to calibrate and validate (Cal/Val) soil moisture data or brightness temperature $(\mathrm{TB})^{17,33,34}$. An important factor leading to minimization of errors of satellite $S M$ retrievals is precise matching the in situ measurement and the satellite sensing depth ${ }^{11}$. Frequently, sensors are placed at depths fitting to mathematical numerical simulations of soil moisture and soil temperature ${ }^{11,35}$ and/or result from the geometry of existing sensors that dictates the location depth ${ }^{31}$.

Although remote sensing using L-band provides valuable information, scientific improvements are still needed in terms of assessment of soil water resources ${ }^{11,16,18,19}$. Therefore, the aim of this study was to assess soil water resources using the new concept Soil Water EXtent at Penetration Depth (SWEX_PD) as the product of soil moisture $(S M)$ and radiation penetration depth $(P D)$, both from SMOS L2 satellite data. The SWEX_PD-SMOSderived soil water resources were validated using ground-monitored soil moisture data at different depths in agrometeorological stations in Poland. Bland-Altman plots were used to quantify the differences between the soil water resources determined by SWEX_PD-SMOS and ground measurements. Assuming that the average water resources from these two methods are equal and their dispersion is within the strictly defined range of the limit of agreement (LoA) and confidence interval (CI), an approach has been proposed to determine the Calibrated Layer Thickness (CLT) and the Equivalent Layer Thickness (ELT) of soil water derived from the SMOS satellite.

\section{Materials and methods}

Study area. The study was conducted in 9 sites in the eastern part of Poland (Fig. 1). Each site is equipped with agrometeorological station measuring soil moisture (SM). The soil moisture data for 2010-2013 (obtained every 3 days) used in the study came from the SMOS satellite (SMUDP2 v. 551) and were provided over the ISEA-4H9 (icosahedral snyder equal area Earth fixed) grid referred to as the discrete global grid (DGG) ${ }^{36}$. The nodes were equally spaced at $15 \mathrm{~km}$. Next, 7 DGG pixels per each site were chosen in a way that the central one (named S0) contained the agrometeorological station and the other 6 (named S1, S2, S3, S4, S5, S6) were bordering around. Real and imaginary part of complex dielectric constant data from SMOS were used to determine the penetration depth using the approach described below.

Penetration depth. The information about soil near-surface layer water resources is required for scientific elucidation of the global water cycle. The idea presented in this paper was to create SWEX_PD (Soil Water EXtent at Penetration Depth) for representing the amount of sub-surface soil water, substituting the surface Soil Moisture (SM) given by SMOS SMUDP2 data files. The multiplying soil moisture $(S M)$ and radiation penetration depth $(P D)$ was first proposed by W. Marczewski to determine uncalibrated soil moisture resources from SMOS measurements ${ }^{37}$.

The Penetration Depth $(P D)$ is derived from dielectric constants based on the Kirchhoff Approach (KA) ${ }^{28}$. The approach assumes that SMOS gathering Temperature Brightness (TB) of emitted radiation over the soil layer thickness $P D$ facilitates not only polarimetric retrieval for $S M$ but also estimation of $P D$ with KA for incoherent radiation. TB is used for determination of the intensity of radiation, while the next aspect is its attenuation by the layer $P D-$ a concept analogical to the optical thickness of soil (also determined by the water). It is believed that, in this way, the surface Soil Moisture may be coupled to the absolute measures of water mass under observation, in kilograms per a particular surface, and the volume of the layer on the $P D$ thickness.

According to the Beer-Lambert law ${ }^{28}$, the intensity of an electromagnetic wave in a uniform media falls off exponentially along the propagation path as 


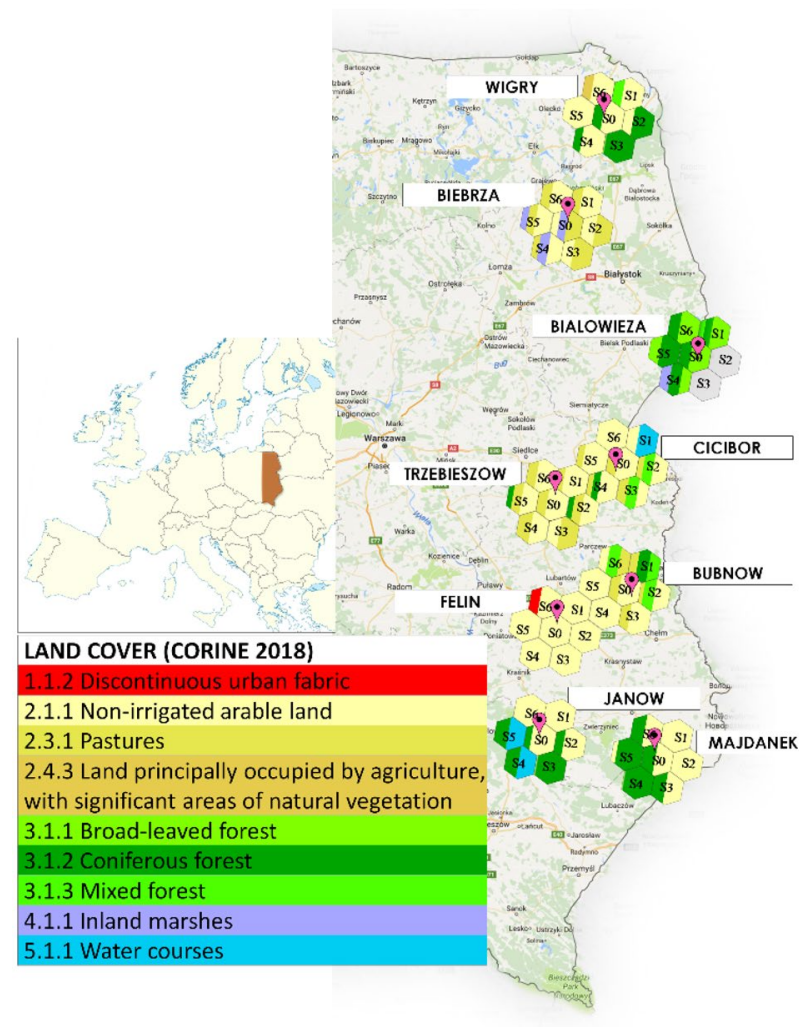

Figure 1. Agrometeorological stations and sites located along the eastern border of Poland with marked pixels from the SMOS satellite and with the structure of the land cover. The surface area occupied by the individual colours in the pixels roughly reflects the surface area occupied by the land cover symbolized by the respective colours. Background maps from Google Maps (https://www.google.com/maps/@52.44051 119.441469,7z?hl=en), accessed 12 Apr. 2017. The background maps were modified using Microsoft Office PowerPoint 2016.

$$
I(z)=I_{0} e^{-\alpha z}
$$

where $I_{0}$ is the electromagnetic wave in the air, $\alpha$ is the attenuation constant. We define the Penetration Depth $(P D)$ for a path of $z$ as a depth at which the intensity of electromagnetic waves decreases $e$ times, where the Euler number $e \approx 2.718$ defines 1 Neper in attenuation terms. We arbitrarily define:

$$
P D=\frac{1}{\alpha}
$$

At depth $z=P D$, the electromagnetic wave components $(\mathrm{E}, \mathrm{H})$ have $1 / e$ of their initial value. Since the power of the $\alpha$ wave in a particular medium is proportional to the square of intensity, the power at Penetration Depth is $1 / e^{2}$, which is $13.5 \%$ of its initial value. The Kirchhoff Approach requires equality of the attenuation for radiation waves propagated by emission from media in two directions, i.e. for outsourcing and incoming waves. The attenuation constant for an electromagnetic wave at a normal incidence angle is proportional to the imaginary part of the material's refractive index $n$. It may be also expressed by the wave-extinction index $\kappa$ :

$$
\alpha=\frac{\omega}{c} \operatorname{Im}(n(\omega))=\frac{2 \pi \kappa}{\lambda_{0}}
$$

where $\omega$ is the angular frequency of radiation, $\lambda_{0}$ is the wavelength, and $c$ is the speed of light in vacuum. The complex refractive index $n$ and complex dielectric constant $\varepsilon$ equally represent the propagation and loss properties of the medium and (in non-ferromagnetic materials) are related by ${ }^{28}$ :

$$
\varepsilon=\varepsilon_{1}+i \varepsilon_{2}=(n+i \kappa)^{2}
$$

where $\varepsilon_{1}$ is the real part and $\varepsilon_{2}$ is the imaginary part of the dielectric constant and $i$ is the imaginary unit. After some simple transformations, one can obtain the conversions: 


$$
n=\sqrt{\frac{\sqrt{\varepsilon_{1}^{2}+\varepsilon_{2}^{2}}+\varepsilon_{1}}{2}} \text { and } \kappa=\sqrt{\frac{\sqrt{\varepsilon_{1}^{2}+\varepsilon_{2}^{2}}-\varepsilon_{1}}{2}}
$$

and find the following formula for Penetration Depth:

$$
P D=\left(2 \pi \sqrt{\frac{\sqrt{(\text { Dielect_Const_RE })^{2}+(\text { Dielect_Const_IM })^{2}}-\text { Dielect_Const_RE }_{-}}{2}}\right)^{-1}
$$

where Dielect_Const is the complex dielectric constant from SMOS L2 data, and RE and IM denote the real and imaginary parts of this complex number, respectively. $P D$ is expressed in $\lambda_{0}$, which for SMOS is $21 \mathrm{~cm}$.

Soil Water EXtent at Penetration Depth (SWEX_PD). The SWEX_PD was proposed for representing the topsoil water amount in relation to the Soil Moisture $(S M)$ at a depth corresponding to the radiometric Penetration Depth $(P D)$ observed by SMOS in SMUDP2. The SWEX_PD concept couples surface SMOS data with the hydrology of deeper soil layers and may be an answer to the need of information about water retention in terms of water mass (in tons per square kilometre).

Uncalibrated "water resources in soil" in the time $j$ step derived from the SMOS satellites were calculated using the $S W E X \_P D_{j k}$ as the product of soil moisture $\left(S M_{j k}\right)$ and radiation penetration depth $\left(P D_{j k}\right)$ for each SMOS pixel $(k=0,1,2, \ldots n)$ :

$$
S W E X \_P D_{j k}=S M_{j k} \times P D_{j k}
$$

$\mathrm{SWEX}_{\mathrm{j}}=\mathrm{SM}_{\mathrm{j}} \times \mathrm{PD}_{\mathrm{j}} \mathrm{SWEX}_{\mathrm{j}}=\mathrm{SM}_{\mathrm{j}} \times \mathrm{PD}_{\mathrm{j}}$ Therefore, $S W E X_{-} P D_{j k}$ is proportional to the soil moisture derived from SMOS but only in $P D_{j k}$ (not applicable to water resources in hydrological terms). $P D_{j k}$ was expressed in a wavelength $\lambda_{0}$ equal to $21 \mathrm{~cm}$ and was determined on the basis of weekly SMOS L2 measurement data based on the dependence of the real and imaginary parts of the dielectric constant.

Ground soil water resources (WR). Ground soil moisture measurement data from various locations and depths were used to determine soil water resources $(W R)$ with the time $j$ step. $W R_{j 0}$ were obtained from the multiplication of ground measured soil moisture $\left(S M_{i 0}\right)$ and layer thickness $d_{i}, i=1,2, \ldots m$ in the central pixel (S0) and then compared with six neighbouring pixels (S1, S2, S3, S4, S5, S6). In the agrometeorological stations located along the eastern border of Poland (Fig. 1), four configurations of three sensors types were used to measure soil moisture. The sensors were installed on grassed soil in four configurations: (1) the PR2 probe was used (at 10, 20,30, 40,60, and $100 \mathrm{~cm}$ depths) (Delta-T) in four stations (Wigry, Biebrza, Białowieża, Trzebieszów), (2) ThetaProbe ML2x sensors were used $(5,20$, and $30 \mathrm{~cm})($ Delta-T) in three stations (Cicibór, Janów Lubelski, Majdanek), (3) a combination of the ThetaProbe ML2x (5 cm) and the PR2 probe (10, 20, 30, 40, 60, and $100 \mathrm{~cm})$ were used in one station (Bubnów), (4) TDR sensors (5, 10, 20, and $40 \mathrm{~cm}$ ) (EasyTest) were used both on grassed (vegetated) and bare (arable) soil in one station (Felin-Lublin). Soil moisture data $\left(S M_{i}\right)$ were averaged weekly for each depth separately. Soil water resources $\left(W R_{j 0}\right)$ were calculated from the sum of components derived from multiplication of soil moisture $\left(S M_{i 0}\right)$ and layer thickness $\left(d_{i}, i=1,2, \ldots m\right)$ and converted to wavelength $\lambda_{0}$ units:

$$
\mathrm{WR}_{\mathrm{j} 0}\left(\frac{\mathrm{SM}_{\mathrm{i} 0} \times \mathrm{d}_{\mathrm{i}}}{\lambda_{0}}\right)=\sum_{\mathrm{i}=1}^{\mathrm{m}} \mathrm{SM}_{\mathrm{i} 0} \times \frac{\mathrm{d}_{\mathrm{i}}}{21}, j=1,2 \ldots, k
$$

where: $m$-number of layers with a known thickness, $\lambda_{0}$ - wavelength $(21 \mathrm{~cm})$ used by the SMOS satellite to measure soil moisture, $j$-time step (week).

Statistical approach. The uncalibrated (unscaled) $S W E X \_P D_{j k}$ water resources derived from the SMOS satellite were compared with the water resources $\left(W R_{j 0}\right)$ derived from ground measurements. To this end, Bland-Altman plots ${ }^{38}$ were adopted as shown below. It was hypothesized that water resources are equal when the average of the differences $S W E X \_P D_{j k}-W R_{j 0}$, the so-called bias, are close to or equal to zero:

$$
\text { bias }=\frac{1}{n} \sum_{j=1}^{n}\left(S W E X \_P D_{j k}-W R_{j 0}\right) \cong 0 \text {, }
$$

and the dispersion of the differences is finite and lies within a well-defined scatter path in the limit of agreement (LoA) and confidence interval (CI), which were calculated from the equations as: LoA $=$ bias $\pm 1.96 \times s$ ( $s$-standard deviation), CI for bias: CI $=$ bias $\pm t \times\left(s^{2} n^{-1}\right)^{0.5}$, and CI for LoA: CI $=\operatorname{LoA} \pm t \times\left(3 s^{2} n^{-1}\right)^{0.5}$, where $n$ is the number of data and $t$ is the value of $t$ distribution with $n-1$ degrees of freedom ${ }^{39}$. The difference between the $S W E X \_P D_{j k}$ and $\left(W R_{j 0}\right)$ derived water resources was adjusted according to the equation:

$$
S W E X_{-} P D_{j k}-W R_{j 0}=a\left(\frac{S W E X \_P D_{j k}+W R_{j 0}}{2}\right)+b
$$

Selection of the Calibrated Layer Thickness $\left(\mathrm{CLT}=d_{\text {bias }}\right)$ at which the bias was close to zero or equal to zero was carried out. Depending on the type of sensors installed in the agrometeorological stations two steps coarse 
and accurate were used. The layer thicknesses in the coarse step for the first sensor in the configurations PR2 probe (1) and the ThetaProbe ML2x (2) were: $d_{i}=5,10$, and $15 \mathrm{~cm}$ and for other sensors they were $d_{i}=5$ and $10 \mathrm{~cm}$. For the configurations ThetaProbe ML2x $(5 \mathrm{~cm})$ and the PR2 probe (3) and TDR sensors (4) the layer thicknesses for the individual sensors were: $d_{i}=5$ and $10 \mathrm{~cm}$. The layer thickness of $1 \mathrm{~cm}$ was taken in the accurate step that allows to minimize the differences in soil water resources between those from satellite and ground-based measurements. The coarse step included the sum of the products of soil moisture $\left(S M_{i}\right)$ and the thickness of the layers given above, checking how much the bias differed from zero. When the bias was much less than zero, the values of $d_{i}$ were decreased by the accurate steps $(1 \mathrm{~cm})$ and chosen so that the bias was close to zero. When the bias was greater than zero, $d_{i}$ was increased by the coarse or accurate steps so that the bias was close to zero. LoA and CI were also calculated to estimate the spread of the analysed data, and the $a$ and $b$ parameters of the linear regression equation were determined (see example in Fig. 2, site Majdanek). Values obtained from the linear regression equation and the bias value (Eq. 11) at the intersection point are equal and correspond to the CLT.

$$
S W E X \_P D_{j k}-W R_{j 0}=a\left(\frac{S W E X \_P D_{j k}+W R_{j 0}}{2}\right)+b=\text { bias }
$$

Only points close to bias on the Bland-Altman plot correspond to the CLT and those much above or below bias have different layer thicknesses resulting in overestimated or underestimated water resources. To reduce the deviations from bias the layer thicknesses were calculated from the transformed regression equation (Eq. 12) so that the regression equation line overlap with bias line (Eq. 13). The layer thickness calculated in this way, referred to as $\left(d_{e i}^{S W E X}\right)$, was named Equivalent Layer Thickness (ELT) that corresponds to water resources derived from the SMOS satellite.

$$
\begin{gathered}
S W E X \_P D_{j k}^{*}=\frac{2(\text { bias }-b)}{a}-W R_{j 0} \\
d_{e i}^{S W E X}=\frac{S W E X \_P D_{j k}^{*} \times d_{b i a s}}{S W E X \_P D_{j k}}=\frac{\left(\frac{2(\text { bias }-b)}{a}-W R_{j 0}\right) \times d_{b i a s}}{S W E X \_P D_{j k}}
\end{gathered}
$$

where $S W E X \_P D_{j k}^{*}$ is the water resource at the intersection point of the regression equation and the bias lines.

Ground measurements in agrometeorological stations. The ranges of sand, silt, and clay in the ground $S M$ measurement stations were 22-97, 1-73, and 2-6\% (Table 1). The Biebrza and Bubnów stations (sites) were partly covered by marsh soils containing up to $80 \%$ of organic matter. The amount of organic matter in some parts of the Białowieża site reached up to $52 \%$. In the other stations, there was $1-3 \%$ of organic matter.

\section{Results}

Comparison of soil water resources from SWEX_PD with ground measurements WR. The use of both coarse and exact steps depending on the SM sensor types and their installation depths allowed estimation (with an accuracy of $1 \mathrm{~cm}$ ) of soil depths at which the soil water resources from ground measurements $\left(W R_{j 0}\right)$ were similar or equal to those from the $S W E X_{-} P D_{j k}$ based on the satellite data, as quantified by the Bland-Altman plots. The statistics including the differences $S W E X \_P D_{j k}-W R_{j 0}$, i.e. bias, LoA, CI, and the linear regression equation $S W E X \_P D_{j k}-W R_{j 0}$ vs. $\left(S W E X \_P D_{j k}+W R_{j 0}\right) / 2$ for pixel S0 are shown in the Bland-Altman plots (Fig. 2). The linear regression equation parameters $(a, b)$ for all pixels (S0-S6) are given in Fig. 3 along with biases at which the $\left(W R_{j 0}\right)$ values were similar or equal to those from the $S W E X \_P D_{j k}$. The majority of $S W E X \_P D_{j k}-W R_{j 0}$ vs. $\left(S W E X \_P D_{j k}+W R_{j 0}\right) / 2$ values were within the defined LoA, some were within CI, and only few were beyond the areas of both LoAs and CIs. Such an arrangement of the data and the bias being close to zero indicated that the effect of the random factor was not significant and that the Bland-Altman approach can be used for the statistical analysis.

As can be seen in Fig. 2, the LoA values for pixels S0 with $S M$ sensors were generally in the range \pm 0.1 . Similarly, the LoAs for the other pixels (S1-S6) in each site were within this range (data not shown). It is worth noting that the largest and smallest LoAs were calculated for the grassed $(> \pm 0.1)$ and arable areas (around \pm 0.07 ), respectively, in the same pixel Felin S0 (Fig. 2). Similarly, the CI values for bias and agreement limits (LoAs) were larger in the Felin-grassed than Felin-arable soil. As the line of equality (zero difference) lies between the confidence interval limits of bias, the latter is not significant. However, the CI of LoAs reached values around 0.02 in the Felin-grassed soil. This indicates that the estimated water resources from these two methods are more compatible in the Felin-arable soil. As can be seen in Fig. 3, the bias values are small (close to zero), positive or negative, in all sites and pixels. The linear regression coefficients $(a)$ of the relationship $S W E X \_P D_{j k}-W R_{j 0}$ vs. $\left(S W E X \_P D_{j k}+W R_{j 0}\right) / 2$ (in Bland-Altman plots) were mostly negative with respective values $<0.5,0.5-1.0$, and $>1$ for 6,33 , and 26 cases. They had positive values (from 0.096 to 1.536 ) only in 3 pixels in the Białowieża site (S0, S2, S6) and 1 pixel both in Trzebieszów (S1) and Felin-arable (S4).

As shown in Fig. 4, the largest calibrated layer thickness derived from the SMOS $\left(d_{b i a s}\right)$ satellite was found in all or most pixels belonging to the Wigry, Biebrza, and Trzebieszów stations (from 26 to $28 \mathrm{~cm}$ ), and lower values were observed in Majdanek, Felin-arable, and Bubnów (from 12 to $14 \mathrm{~cm}$ ). The larger calibrated layer thickness indicates that the same amount of water in a given soil is distributed over a larger depth. The smallest and the largest differentiation of the calibrated layer thickness (from 8 to $15 \mathrm{~cm}$ ) between the pixels was found 

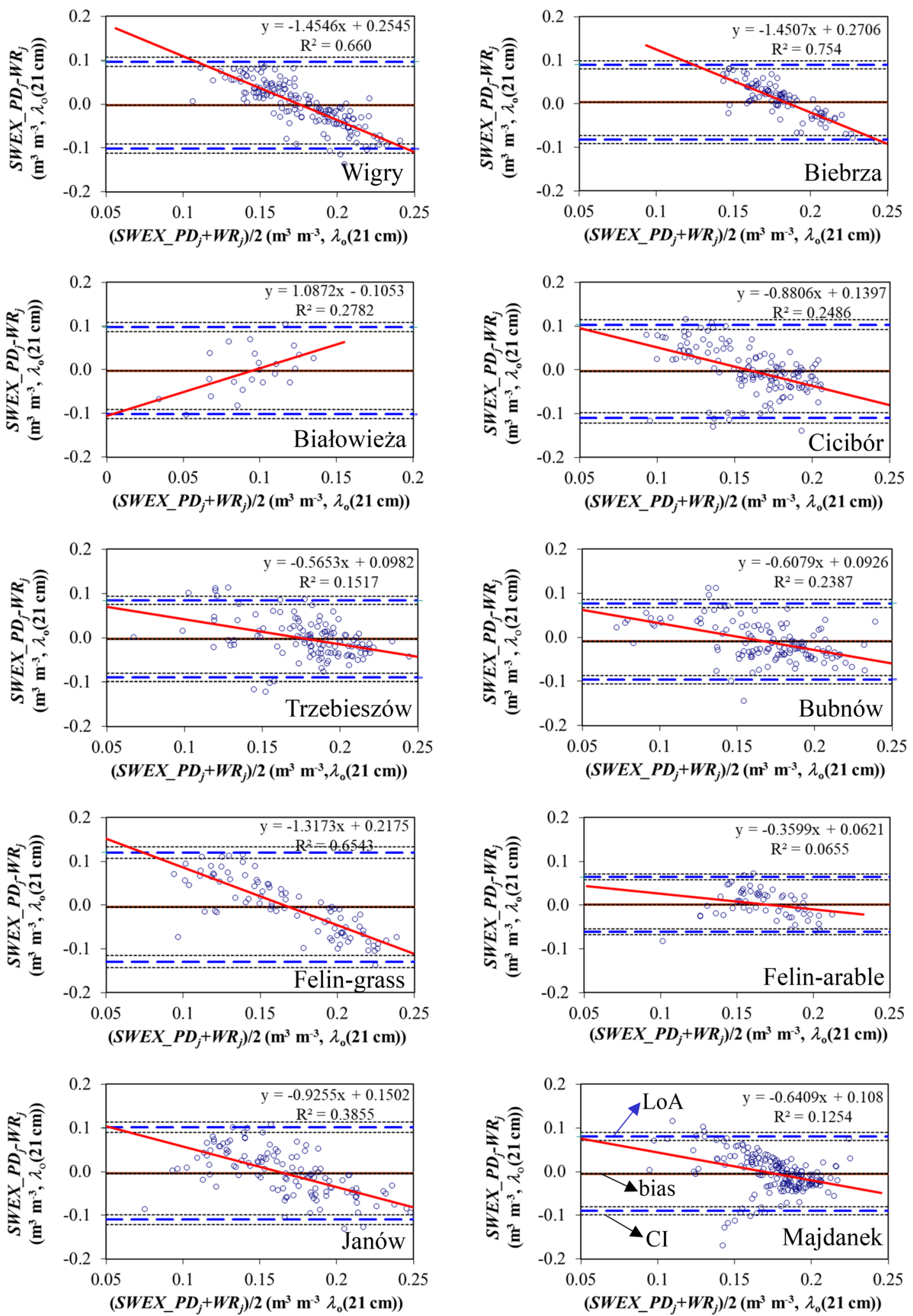

Figure 2. Bland-Altman plot $S W E X \_P D_{j 0}-W R_{j 0}$ vs. $\left(S W E X \_P D_{j 0}+W R_{j 0}\right) / 2$ for $S 0$ pixels depending on the location of the station. Explanations: bias line, limits of agreement (LoA), confidence intervals (CI) for the bias and LoA, regression lines (red) and equations with $\mathrm{R}^{2}$-determination coefficients. 


\begin{tabular}{|c|c|c|c|c|c|}
\hline \multirow[b]{2}{*}{ Name } & \multicolumn{2}{|c|}{ Geographical location } & \multicolumn{3}{|c|}{ Particle size distribution of the soil in the $0-30 \mathrm{~cm}$ layer (\%) } \\
\hline & Longitude $\left({ }^{\circ}\right)$ & Latitude $\left({ }^{\circ}\right)$ & Sand $(2.0-0.05 \mathrm{~mm})$ & Silt $(0.05-0.002 \mathrm{~mm})$ & Clay $(<0.002 \mathrm{~mm})$ \\
\hline Wigry & 23.013536 & 54.060920 & \begin{tabular}{|l|}
87 \\
\end{tabular} & 11 & 2 \\
\hline Biebrza & 22.535407 & 53.301436 & 97 & 1 & 2 \\
\hline Białowieża & 23.847912 & 52.707234 & 68 & 28 & 4 \\
\hline Cicibór & 23.099275 & 52.069369 & 58 & 37 & 5 \\
\hline Trzebieszów & 22.565413 & 51.987345 & 72 & 26 & 2 \\
\hline Bubnów & 23.280621 & 51.374580 & 83 & 15 & 2 \\
\hline Felin & 22.625077 & 51.219703 & 26 & 68 & 6 \\
\hline Janów & 22.418174 & 50.691230 & 86 & 9 & 5 \\
\hline Majdanek & 23.470604 & 50.478213 & 22 & 73 & 5 \\
\hline
\end{tabular}

Table 1. Data on the study sites.

Equivalent water thickness. Based on both the results of the Bland-Altman approach and the equation (Eq. 13) proposed in this study, the equivalent layer thickness $\left(E L T=d_{e i}^{S W E X}\right)$ was determined. The statistics of the ELT including the mean, SD, minimum, maximum, and CV for the central and neighbouring pixels in the 4-year study period (2010-2013) are given in Fig. 4. The overall ranges of variations of the mean ELT, standard deviation (indicated by bars), minimum, maximum, and coefficient of variation (CV) for all pixels and stations were $8.28-28.7 \mathrm{~cm}, 3.27-12.66 \mathrm{~cm}, 3.03-10.87 \mathrm{~cm}, 19.23-94.97 \mathrm{~cm}$, and $24.72-98.79 \%$, respectively. Based on the ELT values, the sites can be divided into three groups. The mean ELT (for all pixels) had the largest values in Trzebieszów, Biebrza, and Wigry (from 25.8 to $28.7 \mathrm{~cm}$ ) and successively decreased in Felin-grassed, Janów, and Cicibór (from 18.4 to $23.9 \mathrm{~cm}$ ) as well as Białowieża, Bubnów, and Majdanek Felin-arable (from 8.3 to $16.8 \mathrm{~cm}$ ).

Overall, the ranges (differences between minimum and maximum values) of the mean, min., max. SD, CV, and $d_{\text {bias }}$ values for (ELT) for all pixels and stations were $20.4 \mathrm{~cm}, 7.8 \mathrm{~cm}, 75.7 \mathrm{~cm}, 9.4 \mathrm{~cm}, 74.1 \%$, and $20.0 \mathrm{~cm}$, respectively (Table 2). The ranges of the maximum ELT values between the pixels (S0-S6) were the smallest in the Majdanek, Trzebieszów, and Wigry sites (to $20 \mathrm{~cm}$ ); intermediate values were found in Felin (arable), Janów, Białowieża, Bubnów, and Felin (grass) (from 20 to $50 \mathrm{~cm}$ ), and the largest values were determined in the Cicibór, Biebrza sites (above $50 \mathrm{~cm}$ ). The largest CV ranges, i.e. 58.3 and $38.1 \%$, recorded for Białowieża and Bubnów, respectively, were approximately 2.5-4.0 times larger than in the other stations $(\leq 15.2 \%)$. The mean and min. values of the ELT in the particular stations were in 15 and 5 cases below $2 \mathrm{~cm}$ and above $2 \mathrm{~cm}$, respectively.

\section{Discussion}

Penetration depth (satellite sensing depth) and resultant soil water resources at a particular time depend on the soil textural composition, which determines the water-holding capacity ${ }^{19,30}$. In general, the penetration depth increases and the water-holding capacity decreases successively in clay, silt, and sandy soils. In our study, the effect of soil texture on the calibrated layer thickness determined by SEWX_PD or soil water resources derived from the SMOS satellite was not explicit. For example, a positive effect of the sand fraction can be clearly seen by comparison of the calibrated layer thickness from 19 to $26 \mathrm{~cm}$ for agricultural soils containing 58-86\% of sand (Cicibór, Trzebieszów and Janów sites) with that from 13 to $18 \mathrm{~cm}$ for soils containing 22-26\% of sand (and $68-73 \%$ of silt) (Majdanek and Felin stations-Table 1, Fig. 4). However, a negative effect of sand was observed while comparing the lower calibrated layer thickness in Biebrza $(26 \mathrm{~cm})$ with that in Wigry $(28 \mathrm{~cm})$ with the respective sand content of 97 and $87 \%$. The lower calibrated layer thickness "seen" in the Biebrza station may result from the presence of organic matter-rich marshes (up to $80 \%$ ), which retain much more water than inherently permeable sandy soils ${ }^{40}$. Also in the Bubnów site, the "seen" calibrated layer thickness was relatively small $(10-12 \mathrm{~cm})$ despite the relatively high content of sand (83\%). Bubnów, similarly to Biebrza and Białowieża (52\%), also had large amounts of organic matter in soil reaching up to $80 \%$.

Our results showed the largest ranges of the 4 -year calibrated layer thickness $\left(\mathrm{CLT}=d_{\text {bias }}\right)$ derived from the SMOS satellite $(8-15 \mathrm{~cm})$, equivalent layer thickness $\left(E L T=d_{e i}^{S W E X}\right)($ from 8.3 to $16.09 \mathrm{~cm})$, and coefficient of variation (CV) (from 40.5 to 99\%) (Fig. 4) between the pixels in the Białowieża site. This site is situated in Białowieża National Park on the territory of Poland and Belarus with well-preserved forests and biological diversity, including the rare European bison. The area within the station is highly heterogeneous due to the spatial variation of soil organic matter content, textural composition, wetness, and vegetation. The area offers a diversity of conditions that influence the SMOS penetration depth retrievals. The analysis of the satellite-based pictures has demonstrated that the differences in the "seen" soil water resources (similarly, the differences in the equivalent layer thickness) between the pixels can be influenced by the type of predominant trees, i.e. either deciduous or coniferous. This can be illustrated by comparison of the relatively high CLT of $15 \mathrm{~cm}$ in pixel S5 covered predominantly by a coniferous forest with that of $8 \mathrm{~cm}$ in pixels S0 and S6 with predominance of broadleaved forests (Figs. 1 and 4). Broad-leaved trees vs. coniferous trees have a larger surface leaf area and (thus) water content, which may have a masking effect on the water "seen" in the soil ${ }^{17}$ due to the presence of hydrogen stored in the vegetation affecting the counts of neutrons registered by the sensor ${ }^{19}$. The slight impact of coniferous trees can be supported by the same equivalent layer thickness "seen" $(28 \mathrm{~cm})$ in all pixels within the Wigry site consisting of four pixels (S0, S1, and S4-S6) used mostly as arable lands and two pixels (S2 and S3) covered by 


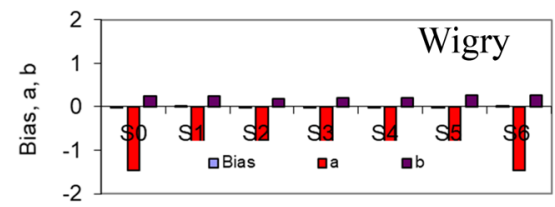

pixel (S0-S6)

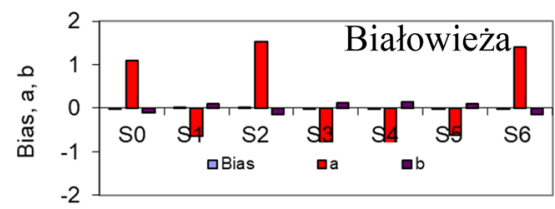

pixel (S0-S6)

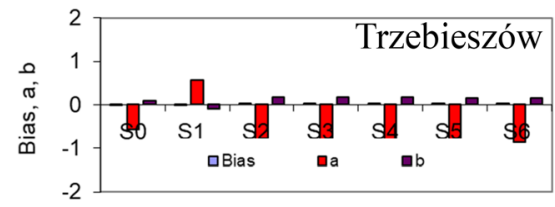

pixel (S0-S6)

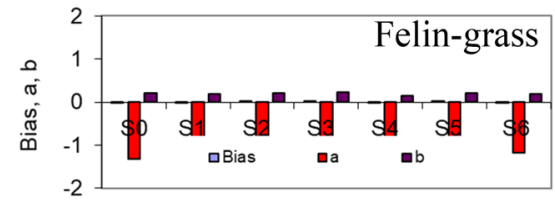

pixel (S0-S6)

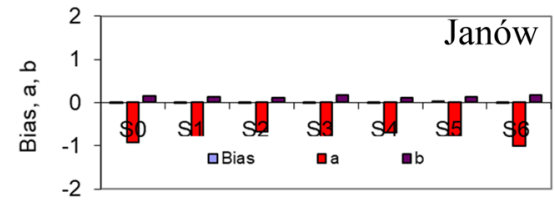

pixel (S0-S6)

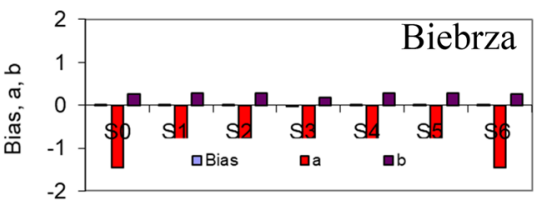

pixel (S0-S6)

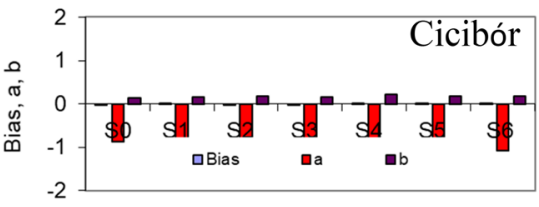

pixel (S0-S6)

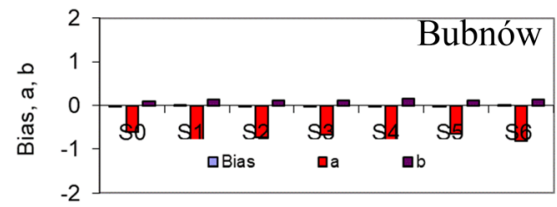

pixel (S0-S6)

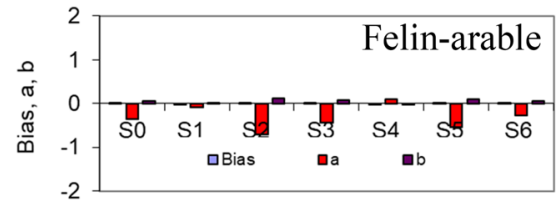

pixel (S0-S6)

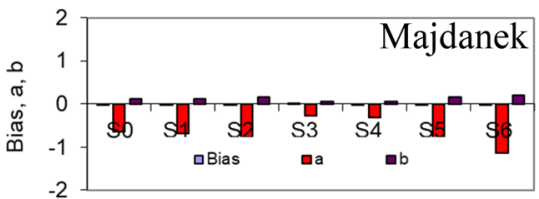

pixel (S0-S6)

Figure 3. Bias and parameters of regression lines: $\mathrm{a}$ and $\mathrm{b}(\mathrm{y}=\mathrm{ax}+\mathrm{b})$ for $\mathrm{S} 0-\mathrm{S} 6$ pixels depending on the location of the site from the Bland-Altman plots.

coniferous trees. (Fig. 1) In connection with this, a recent study in the tropics on the Tibetan Plateau revealed ${ }^{11}$ that dense vegetation and associated small SMOS/SMAP-derived penetration depth need to be calibrated in contrast to limited or no vegetation in the dessert area exhibiting large penetration depth. El Hajj et al. ${ }^{14}$ reported that the $\mathrm{L}$ bands (in $\mathrm{HH}$ polarization) penetrated a well-developed canopy cover of wheat and grasslands at the Normalized Difference Vegetation Index (NDVI) $>0.7$ (the backscattered L-HH is sensitive to soil moisture), whereas the penetration of the C-band into the canopy was limited for an NDVI $<0.7$.

The variability in the equivalent layer thickness derived from the SMOS satellite among the pixels in the Białowieża site within Białowieża National Park can be further affected by the remaining dead trees. The presence of water accumulated in dead trees (not included in the estimation of soil moisture derived from the SMOS satellite) may have resulted in the lowest water depth "seen" $(8 \mathrm{~cm})$ in the soil in the forested areas within pixels S0 and S6 (Fig. 1) of the station. This effect can be more influenced by fallen than standing trees because the former can accumulate water ${ }^{41}$. It is worth noting that the low equivalent layer thickness "seen" in unforested pixel S2 can be influenced by organic matter in the marshes (52\%) occurring in this pixel (Fig. 1). We observed visually that organic matter-rich soils $(\mathrm{S} 1, \mathrm{~S} 4)$ were saturated with water for most of the year and their topsoil is moist or 

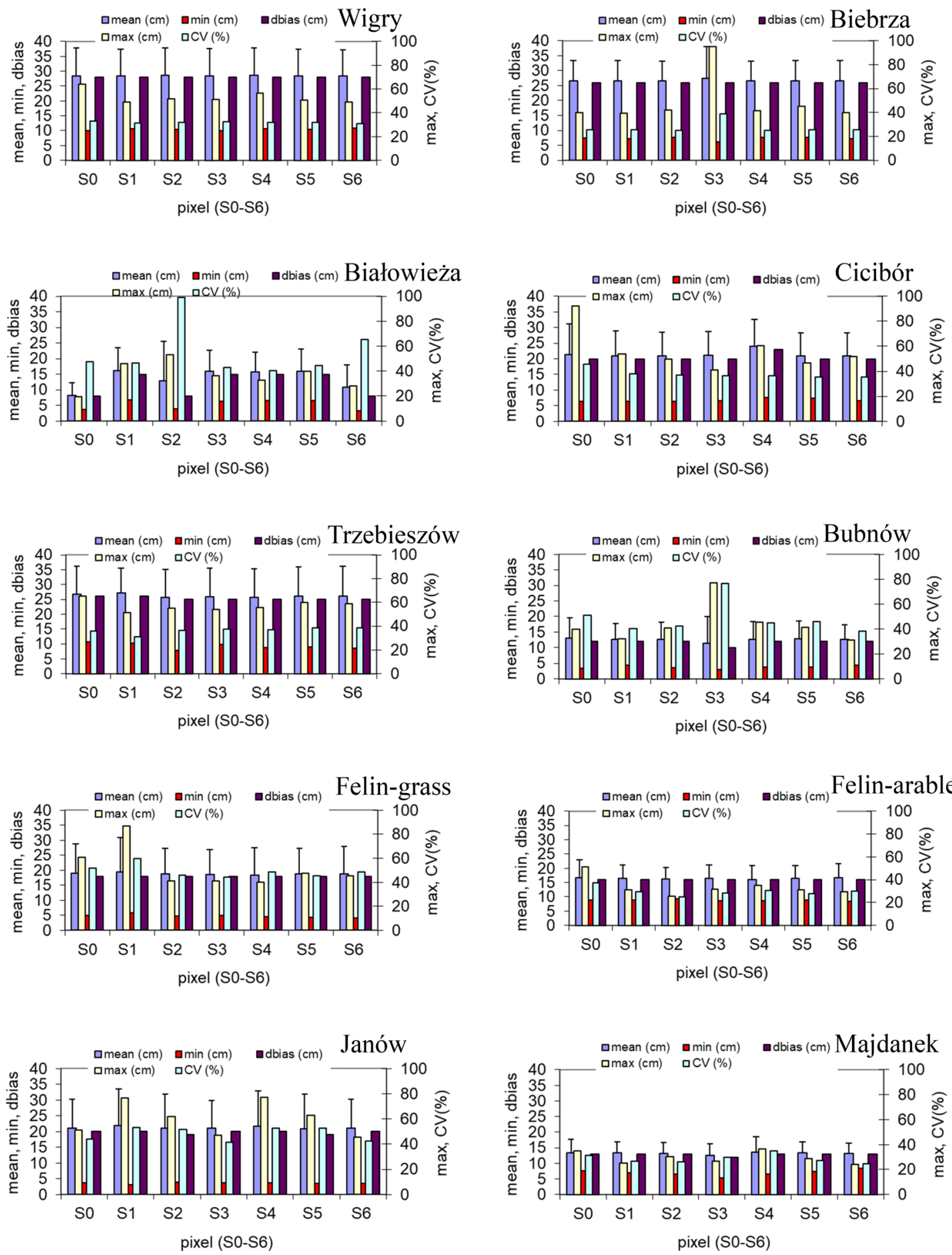

Figure 4. Statistical parameters of equivalent layer thickness (ELT) and calibrated layer thickness (CLT) for data from all pixels (S0-S6) in each station. Explanations: ELT-mean (from 8.28 to $28.7 \mathrm{~cm}$ ) with bars of standard deviation (from 3.27 to $12.66 \mathrm{~cm}$ ), minimum (from 3.03 to $10.87 \mathrm{~cm}$ ), maximum (from 19.23 to $94.97 \mathrm{~cm}$ ), and coefficient of variation CV(\%) (from 24.72 to $98.79 \%$ ), and CLT_dbias (from the surface up to $8-28 \mathrm{~cm}$ depth).

sometimes dry only in the summer. In pixel S2 (in Belarus), the low "seen" calibrated layer thickness can also be influenced by the high content of silt (to 40\%) and clay (to 11\%) in the soil cover and organic matter in marshes.

The effect of vegetation on the "seen" calibrated layer thickness $\left(d_{\text {bias }}\right)$ is also visible while comparing the grassed (vegetated) and bare (arable) on the same (loess) soil within the Felin station. The greater calibrated layer thickness derived from the SMOS satellite for the grassed than bare soil $(18 \mathrm{vs} .16 \mathrm{~cm})$ can be a result of water uptake by grasses and the associated decrease in the soil water content and dielectric constant. On the other 


\begin{tabular}{|l|l|l|l|l|l|l|l|l|l|l|l|}
\hline Range, ELT $(\mathbf{c m})$ & Wigry & Biebrza & Białowieża & Cicibór & Trzebieszów & Bubnów & Felin grass & Felin arable & Janów & Majdanek & $\begin{array}{l}\text { All pixels and } \\
\text { stations }\end{array}$ \\
\hline Mean & 0.30 & 0.90 & 7.83 & 3.07 & 1.39 & 1.66 & 0.96 & 0.68 & 0.91 & 1.15 & 20.4 \\
\hline Min & 0.92 & 1.51 & 3.35 & 1.23 & 2.86 & 1.39 & 1.55 & 0.76 & 0.75 & 3.06 & 7.8 \\
\hline Max & 15.1 & 55.7 & 34.1 & 51.6 & 14.0 & 46.2 & 47.0 & 25.5 & 31.6 & 12.6 & 75.7 \\
\hline SD & 0.60 & 3.99 & 8.73 & 2.35 & 1.67 & 3.85 & 3.31 & 2.18 & 2.84 & 1.50 & 9.4 \\
\hline CV $(\%)$ & 2.1 & 13.8 & 58.3 & 10.1 & 7.7 & 38.1 & 15.2 & 12.3 & 11.6 & 10.2 & 74.1 \\
\hline d bias & 0.0 & 0.0 & 7.0 & 3.0 & 1.0 & 2.0 & 0.0 & 0.0 & 1.0 & 1.0 & 20.0 \\
\hline
\end{tabular}

Table 2. Ranges of the statistical parameters of equivalent layer thickness (ELT) and calibrated layer thickness (dbias) for data from all pixels in each station and from all pixels and stations. Explanations: min minimum, max maximum, $S D$ standard deviation, and $C V(\%)$ coefficient of variation.

hand, in spite of the water uptake in soil covered by vegetation vs. bare soil, the dielectric constant can be higher in the former due to the lower evaporation from the soil surface ${ }^{30}$. This indicates that the "seen" calibrated layer thickness is affected by interactions between soil texture and vegetation.

It is worth noting that the equivalent layer thicknesses (ELT) for the Majdanek and Felin sites varying from about 5 to $25 \mathrm{~cm}$ during the study period were comparable to "sensing depth" from $8 \mathrm{~cm}$ in March to $27 \mathrm{~cm}$ in July observed in the SMOSREX (Surface Monitoring Of the Soil Reservoir EXperiment) microwave measurement campaign with similar soil ${ }^{31,42}$. Considering different sensing depths in the SMOSREX revealed that the agreement in soil moisture between the model-predicted data with consideration of the brightness temperature in the L band and measured data was satisfactory at depth of $0-5 \mathrm{~cm}$ which is concurrent with global surface soil moisture provided by the SMOS satellite ${ }^{23}$. In the case of spatially variable soils, the compliance of soil moisture from satellite and ground measurements in soil profile can be improved by using combined active, passive microwave and optical methods, with different penetration depths in airborne flights ${ }^{43}$. On the other hand, the obtained real and imaginary dielectric constants from the measurements of the SMOS brightness temperature allow to determine penetration depth and soil moisture using available methods ${ }^{23,28,42}$. The SWEX_PD and the approach proposed in this paper allowed for the determination of the calibrated and equivalent layer thicknesses which are consistent with the sensing depths $(8-27 \mathrm{~cm})$ obtained in the SMOSREX measurement campaign ${ }^{42}$ and justify the use of SMOS SM data in our study. More detailed investigations are needed to address these interactions and enhance the usability of the satellite $S M$ products (retrievals).

\section{Summary and conclusions}

The following findings were shown in this study:

1. The SWEX_PD was proposed for the first time to assess soil water resources based on 4-year SMOS satellite data and to determine the equivalent layer thickness derived from the SMOS satellite. The assessments were verified in nine sites under different soils and land cover (vegetation) in Poland.

2. The Bland-Altman plots including the bias, limits of agreements, and confidence intervals showed that the effect of a random factor was not significant and indicated that the soil water resources and equivalent layer thickness values were estimated with satisfactory accuracy.

3. Depending on the site conditions, the values of the equivalent layer thickness varied from 8.3 to $28.7 \mathrm{~cm}$. This variation was mostly attributed to differences in soil texture, organic matter, and vegetation and interactions between them. It was observed that the negative effect of the sand content on equivalent layer thickness values was masked (or compensated for) by the abundant organic matter in marsh soils and broad-leaved forest cover. The higher values of the equivalent layer thickness for the grassed than bare silt (loess) soil were ascribed to plant water absorption in the former.

4. Highly heterogeneous conditions in terms of soil organic matter, textural composition, wetness, and vegetation in one site situated within Białowieża National Park were reflected in a wide range of equivalent layer thickness values $(8.26-16.09 \mathrm{~cm})$ and spatial variability of the soil water resources $(\mathrm{CV}<98.8 \%)$.

5. Further studies are intended to address the impact of the soil conditions and land cover more comprehensively to improve the assessment of soil water resources using satellite retrievals.

Received: 28 April 2020; Accepted: 15 October 2020

Published online: 27 October 2020

\section{References}

1. Seneviratne, S. I. et al. Investigating soil moisture-climate interactions in a changing climate: a review. Earth Sci. Rev. 99, 125-161 (2010).

2. Paltineanu, C., Chitu, E. \& Tanasescu, N. Correlation between the crop water stress index and soil moisture content for apple in a loamy soil: a case study in Southern Romania. Acta Hortic. 889, 257-264 (2011).

3. Saseendran, S. A. et al. Quantifying crop water stress factors from soil water measurements in a limited irrigation experiment. Agric. Syst. 137, 191-205 (2015).

4. Usowicz, B., Lipiec, J. \& Lukowski, M. Evaluation of soil moisture variability in Poland from SMOS satellite observations. Remote Sens. 11, 1-16. https://doi.org/10.3390/rs11111280 (2019). 
5. Yamada, T. J., Kanae, S., Oki, T. \& Hirabayashi, Y. The onset of the West African monsoon simulated in a high-resolution atmospheric general circulation model with reanalyzed soil moisture fields. Atmos. Sci. Lett. 13, 103-107 (2012).

6. Lim, Y. J., Hong, J. \& Lee, T. Y. Spin-up behavior of soil moisture content over East Asia in a land surface model. Meteorol. Atmos. Phys. 118, 151-161 (2012).

7. Berg, A. et al. Impact of soil moisture-atmosphere interactions on surface temperature distribution. J. Clim. 27, 7976-7993 (2014).

8. EASAC. Opportunities for Soil Sustainability in Europe (EASAC Policy Report 36). Halle, Germany (2018)

9. Kerr, Y. H. Soil moisture from space: where are we?. Hydrogeol. J. 15, 117-120. https://doi.org/10.1007/s10040-006-0095-3 (2007).

10. De Rosnay, P. et al. AMMA land surface model intercomparison experiment coupled to the Community Microwave Emission Model: ALMIP-MEM. J. Geophys. Res. Atmos. https://doi.org/10.1029/2008JD010724 (2009).

11. Lv, S., Zeng, Y., Wen, J., Zhao, H. \& Su, Z. Estimation of penetration depth from soil effective temperature in microwave radiometry. Remote Sens. 10, 519 (2018).

12. Makwana, J. J. \& Tiwari, M. K. Intermittent streamflow forecasting and extreme event modelling using wavelet based Artificial Neural Networks. Water Resour Manage 28, 4857-4873. https://doi.org/10.1007/s11269-014-0781-1 (2014).

13. Cepuder, P. \& Nolz, R. Irrigation management by means of soil moisture sensor technologies. J. Water Land Dev. 11, 79-90 (2007).

14. El Hajj, M., Baghdadi, N., Bazzi, H. \& Zribi, M. Penetration analysis of SAR signals in the C and L bands for wheat, maize, and grasslands. Remote Sens. 11, 31. https://doi.org/10.3390/rs11010031 (2019).

15. Al-Yaari, A. et al. Global-scale comparison of passive (SMOS) and active (ASCAT) satellite based microwave soil moisture retrievals with soil moisture simulations (MERRA-Land). Remote Sens. Environ. 152, 614-626 (2014).

16. Kerr, Y. H. et al. The SMOS soil moisture retrieval algorithm. IEEE Trans. Geosci. Remote Sens. 50, 1384-1403 (2012).

17. Al-Yaari, A. et al. The AQUI soil moisture network for satellite microwave remote sensing validation in South-Western France. Remote Sens. 10, 1839. https://doi.org/10.3390/rs10111839 (2018).

18. Calvet, J.-C. et al. Sensitivity of passive microwave observations to soil moisture and vegetation water content: L-band to W-band. IEEE Trans. Geosci. Remote Sens. 49, 1190-1199. https://doi.org/10.1109/TGRS.2010.2050488 (2011).

19. Mohanty, B. P., Cosh, M. H., Lakshmi, V. \& Montzka, C. Soil moisture remote sensing: State-of-the-science. Vadose Zone J. https ://doi.org/10.2136/vzj2016.10.0105 (2017).

20. Toride, K., Sawada, Y., Aida, K. \& Koike, T. Toward high-resolution soil moisture monitoring by combining active-passive microwave and optical vegetation remote sensing products with Land Surface Model. Sensors 19, 3924. https://doi.org/10.3390/s1918 3924(2019) (2019).

21. Entekhabi, D. et al. The soil moisture active passive (SMAP) mission. Proc. IEEE 98, 704-716 (2010).

22. Escorihuela, M. J. et al. A simple model of the bare soil microwave emission at L-band. IEEE Trans. Geosci. Remote Sens. 45, 1978-1987 (2007).

23. Kerr, Y. H. et al. The SMOS mission: New tool for monitoring key elements of the global water cycle. Proc. IEEE 98, 666-687 (2010).

24. Querol, J., Perez, A. \& Camps, A. A. Review of RFI mitigation techniques in microwave radiometry. Remote Sens. 11, 3042 (2019).

25. González-Zamora, Á., Sánchez, N., Martínez-Fernández, J. \& Wagner, W. Root-zone plant available water estimation using the SMOS-derived Soil Water Index. Adv. Water Resour. 96, 339-353 (2016).

26. De Lannoy, G. J. M. \& Reichle, R. H. Assimilation of SMOS brightness temperatures or soil moisture retrievals into a land surface model. Hydrol. Earth Syst. Sci. 20, 4895-4911. https://doi.org/10.5194/hess-20-4895-2016 (2016).

27. Muñoz-Sabater, J. Incorporation of passive microwave brightness temperatures in the ECMWF soil moisture analysis. Remote Sens. 7, 5758-5784. https://doi.org/10.3390/rs70505758 (2015).

28. Fox, M. Optical Properties of Solids 2nd edn, 3 (Oxford University Press, Oxford, 2010).

29. Singh, A., Meena, G. K., Kumar, S. \& Gaurav, K. Analysis of the effect of incidence angle and moisture content on the penetration depth of L- and S-band SAR signals into the ground surface, ISPRS. Ann. Photogramm. Remote Sens. Spatial Inf. Sci. 5, 197-202. https://doi.org/10.5194/isprs-annals-IV-5-197-2018 (2018).

30. Gharechelou, S., Tateishi, R. \& Sumantyo, J. T. S. Interrelationship analysis of L-band backscattering intensity and soil dielectric constant for soil moisture retrieval using PALSAR Data. Adv. Remote Sens. 4, 15-24. https://doi.org/10.4236/ars.2015.41002 (2015).

31. Escorihuela, M. J., Chanzy, A., Wigneron, J. P. \& Kerr, Y. H. Effective soil moisture sampling depth of L-band radiometry: a case study. Remote Sens. Environ. 114, 995-1001 (2010).

32. Scheeler, R., Kuester, E. F. \& Popovic, Z. Sensing depth of microwave radiation for internal body temperature measurement. IEEE Trans. Antennas Propag. 62, 1293-1303 (2014).

33. Colliander, A. et al. Validation of SMAP surface soil moisture products with core validation sites. Remote Sens. Environ. 191, 215-231 (2017).

34. Bai, J. et al. Assessment of the SMAP-Derived Soil Water Deficit Index (SWDI-SMAP) as an Agricultural Drought Index in China. Remote Sens. 10, 1302. https://doi.org/10.3390/rs10081302www.mdpi(2018) (2018).

35. Lv, S., Zeng, Y., Su, Z. \& Wen, J. A closed-form expression of soil temperature sensing depth at L-band. IEEE Trans. Geosci. Remote Sens. 57(7), 4889-4897. https://doi.org/10.1109/TGRS.2019.2893687 (2019).

36. Kerr, Y. H. et al. Soil moisture retrieval from space: the soil moisture and ocean salinity (SMOS) mission. IEEE Trans. Geosci. Remote Sens. 39, 1729-1735 (2001).

37. Łukowski, M., Usowicz, B., Usowicz, J., Słomiński, J., Rojek, E. \& Marczewski, W. Soil surface water resources assessment from SMOS L2 and in situ data for Poland. 2nd SMOS Science Conference, ESA-ESAC, Villafranca, Madrid, Spain, 24-29 (2015)

38. Bland, J. M. \& Altman, D. G. Statistical method for assessing agreement between two methods of clinical measurement. The Lancet 327(8476), 307-310 (1986).

39. Giavarina, D. Understanding Bland altman analysis. BioChem. Med. 24, 141-151 (2015).

40. Gnatowski, T., Szatylowicz, J., Brandyk, T. \& Kechavarzi, C. Hydraulic properties of fen peat soils in Poland. Geoderma 154, 188-195. https://doi.org/10.1016/j.geoderma.2009.02.021 (2010).

41. Barr, P. M. The effect of soil moisture on the establishment of spruce reproduction in British Columbia. Yale School For. Bull. 26, 78 (1930).

42. Holmes, T. et al. A new parameterization of the effective temperature for L-band radiometry. Geophys. Res. Lett. https://doi. org/10.1029/2006GL025724 (2006).

43. Zhao, T. et al. Soil moisture experiment in the Luan River supporting new satellite mission opportunities. Remote Sens. Environ. 240, 111680 (2020).

\section{Acknowledgements}

The research was partially conducted under the projects "Water in soil -satellite monitoring and improving the retention using biochar" no. BIOSTRATEG3/345940/7/NCBR/2017, which was financed by the Polish National Centre for Research and Development in the framework of "Environment, agriculture and forestry" BIOSTRATEG strategic R\&D programme and the ELBARA_PD (Penetration Depth) project No. 4000107897/13/ NL/KML funded by the Government of Poland through an ESA (European Space Agency) contract under the PECS (Plan for European Cooperating States). 


\section{Author contributions}

B.U. proposed equivalent layer thickness to determine soil water resources. M.L. and J.L. described how soil texture and land cover are related with the soil water resources. All authors jointly quantified the agreement between the water resources and ground measurements and wrote the paper.

\section{Competing interests}

The authors declare no competing interests.

\section{Additional information}

Correspondence and requests for materials should be addressed to B.U.

Reprints and permissions information is available at www.nature.com/reprints.

Publisher's note Springer Nature remains neutral with regard to jurisdictional claims in published maps and institutional affiliations.

(c) (i) Open Access This article is licensed under a Creative Commons Attribution 4.0 International License, which permits use, sharing, adaptation, distribution and reproduction in any medium or format, as long as you give appropriate credit to the original author(s) and the source, provide a link to the Creative Commons licence, and indicate if changes were made. The images or other third party material in this article are included in the article's Creative Commons licence, unless indicated otherwise in a credit line to the material. If material is not included in the article's Creative Commons licence and your intended use is not permitted by statutory regulation or exceeds the permitted use, you will need to obtain permission directly from the copyright holder. To view a copy of this licence, visit http://creativecommons.org/licenses/by/4.0/.

(C) The Author(s) 2020 